\title{
PHYSICAL OBJECTS, PHYSICAL THEORIES AND WHAT IS PHYSICAL IN PHYSICALISM ${ }^{1}$
}

\author{
Rodrigo Azevedo dos Santos Gouvea
}

UFSJ

\begin{abstract}
Resumo: Muitas tentativas malsucedidas de solucionar o problema de caracterizar o que é físico para o fisicalismo foram baseadas em um ou em outro aspecto de nosso conceito de físico, como a noção intuitiva de objeto físico ou a noção de físico como correspondendo ao domínio de investigação da física. O artigo apresenta uma tentativa original de solução do referido problema ao considerar nosso conceito filosófico de físico de uma forma mais abrangente. Argumenta que a noção intuitiva de objeto físico executa um papel na determinação da tarefa explanatória da física atual. Uma vez que a física ideal é uma idealização da física atual a respeito do sucesso na busca de seus objetivos, nós conhecemos uma tarefa explanatória da física ideal e, consequentemente, parte de seu conteúdo. Ao apelar a uma física ideal, cujo conteúdo conhecemos parcialmente, o artigo pretende caracterizar o que é físico para o fisicalismo.
\end{abstract}

Palavras-chave: Fisicalismo; objetos físicos; teorias físicas; física ideal.

\begin{abstract}
Many failed attempts to solve the problem of characterizing what is physical in physicalism were based on one or another aspect of our (cluster) concept of physical, such as the intuitive notion of physical object or the notion of physical as corresponding to the subject matter of physics. The paper presents an original attempt to solve the mentioned problem by considering our concept of physical in a more comprehensive way. It argues that the intuitive notion of physical object plays a role in determining an explanatory task of current physics. Since ideal physics is an idealization of current physics in respect to the success in the pursuit of its aims, we know an explanatory task of the ideal physics and, thus, part of its content. By appealing to ideal physics, whose content is known to us to a certain extent, the paper attempts to characterize what is physical in physicalism.
\end{abstract}

Keywords: Physicalism; physical objects; physical theories; ideal physics.

\section{Introduction}

The metaphysical doctrine of physicalism can be presented by the slogans 'everything there is physical' and 'there is nothing over and above the physical.' In order to make sense of these and other physicalist claims, one immediately faces the problem of characterizing what is physical. In dramatic terms, the intelligibility of physicalism is at stake if the physical domain is not delimited or specified.

\footnotetext{
1 The research was developed at the Universität Lepzig and at the Universidade Federal de São João del-Rei. This work was supported by the German Academic Exchange Service (DAAD) under the number A/08/71864.
} 
Both sympathizers and critics of physicalism have pointed out difficulties and challenges to any attempt to fulfill the task of characterizing what is physical. Among the critics, some have concluded that the difficulties are insurmountable, and that physicalism is a vacuous doctrine (CRANE and MELLOR, 1990, pp. 186s \& 206). Others have argued that, since physicalism is strongly associated to the physical theories of the day, "which vary with time', it should not be conceived as a factual claim about what there is, but only as an attitude, amusingly called 'the spirit of materialism' (VAN FRAASSEN, 1996, p. 164).

The main aim of this paper is to argue for the acknowledgment of a strict notion of physical, one that overcomes the difficulties that stand against any attempt to characterize what is physical. Such a notion of physical would ensure, in this respect, the intelligibility of physicalism. Since the significance of the problem of characterizing what is physical derives from the fact that it poses a threat for physicalism, I refer to it as the physicalist problem of characterizing physical (in short, PPP). The difficulties pointed out in the specialized literature are described and confronted in the course of my discussion of some attempts to solve PPP. The former attempts to characterize what is physical, which succumbed to the difficulties associated to PPP, have been informed only by singular aspects of our philosophical concept of physical. In contrast, the solution I present in this paper to PPP is informed by this concept in a more comprehensive way.

\section{Our (philosophical) concept of the physical}

A natural starting-point for an investigation intended to grasp a solution to the physicalist problem of characterizing physical is to consider the meaning currently attributed to the term 'physical'. After analyzing the uses of the term 'physical property' in contemporary philosophical discourse, Daniel Stoljar concludes that its meaning should be conceived as a cluster concept (STOLJAR 2010, p. 55). According to this assumption, the term 'physical' might be understood in different ways; each way being determined by one or more features that work as criteria for something to be conceived as physical. To make this point clear, consider that we usually take tables and chairs, as well as fields of force and light waves to be physical. Tables and chairs are said to be physical because we usually refer to spatial-temporal non-living objects in this way. Ned Markosian calls this view 'the Common Sense Account of Physical Objects' (2000, p. 383). Fields of force and light waves, on the other hand, are said to be physical because there are references to them in scientific physical theories. The fact that the term 'physical' is applied to things of such different kinds is not problematic. In the case of cluster concepts, the different 
criteria that guide the use of a term, i.e., the singular or combined elements of a cluster, must all be considered legitimate.

Stoljar's analysis of the concept of physical property reveals five criteria (or elements of the cluster concept) that diversely determine the use of the term 'physical' among philosophers (STOLJAR, 2010, p. 56). Unlike Stoljar, I avoid here the discussion of whether physicalists are concerned only with physical properties or also with physical entities of other ontological kinds, such as physical objects or physical events. For this reason, I present a modified version of his account, substituting his references to physical properties for references to what would be physical in general. According to this analysis (cf. STOLJAR 2010, pp. 56f.), the term 'physical' applies to $x$ if:

(Object): $x$ is an intuitively recognized physical object;

(Theory): $x$ is expressed by a predicate of a physical theory;

(Objectivity): $x$ is objective;

(Method): $x$ is something we could come to know about through the methods of science;

(Contrast): $x$ is not a soul, ectoplasm, an ESP, etc. In other words, $x$ is not a mental entity (substance, property, etc) that cannot be, by definition, identical with something physical.

Most of the attempts to characterize the notion of physical for physicalism were based on the (Object) or on the (Theory) criterion. Nonetheless, there are some, less promising attempts to characterize what is physical by means of the (Method) and (Objectivity) criteria, as well as the (Contrast) criterion.

The (Method) and (Objectivity) criteria for using the term 'physical' restrict the domain of the physical to the things that can be acknowledged by the natural sciences. According to Stoljar, these criteria characterize instances of the physical as (i.) being knowable to anyone, i.e., independently of subjective psychological features, and as (ii.) being accessible through the methods distinctively employed in the natural sciences (STOLJAR, 2010, p. 83). From the association of the notion of physical with the methods of the natural sciences, one can infer some features of physical things. David Spurrett and David Papineau, e.g., say that, according to 'the scientific programme instituted by Galileo, Descartes and Newton', science 'deals only in measurable quantities' (1999, p. 27). Though we may determine some features of physical things, this clearly does not suffice as a characterization of what is physical. The domain delimited by the (Method) and the (Objectivity) criteria encompasses all natural phenomena. If we apply those criteria without further restriction, we end up including in the physical domain entities that traditionally belong to the domains of other natural sciences. Some physicalists have held this position (see BRADDON-MITCHELL \& JACKSON, 1996, 
pp. 13f.). Nonetheless, I claim that a less permissive characterization is at hand if we consider the (Theory) and the (Object) criteria.

The (Contrast) criterion was employed in the approach to characterize the physical known as the 'via negativa' (cf. MONTERO and PAPINEAU, 2005). It is based on the controversial claim that we know the features of mental entities independently of our knowledge of the physical, and then proceed with the via negativa. In Stoljar's view, the (Contrast) criterion does not exclude all supposed mental entities from the physical domain, but only the 'clear cases of things that are both mental and non-physical' (STOLJAR, 2010, p. 82). But what are those things? Gilbert Ryle argues in a very compelling way that part of the knowledge we have of the so-called mental substances is obtained by denying them some features we find amongst the physical (1963 [1949], p. 21). Mental substances are said to be non-spatial, not public, and not being subjected to the physical laws. Certainly, Ryle's claim that the dualists characterize the mental by means of a via negativa is controversial. Nonetheless, it has some appeal, especially for physicalists. If Ryle is right, then it does not make sense to make use, once again, of the via negativa to characterize the physical. We would know what is physical before knowing what a mental substance would be. The following two sections present the difficulties faced by the (Object) criterion approach and the (Theory) criterion approach.

\section{The (Object) criterion approach}

The (Object) criterion presents as physical everything that can be intuitively recognized as a physical object. The fact that this recognition is intuitive reveals that not a technical, but an everyday concept of physical object is employed ${ }^{2}$. Peter van Inwagen analyzes this notion and concludes that:

A thing is a material object if it occupies space and endures
through time and can move about in space (literally move
about, unlike a shadow or a wave or a reflection) and has a
surface and has a mass and is made of certain stuff or stuffs.
Or, at any rate, to the extent that one was reluctant to say of
something that it had various of these features, to that extent
one would be reluctant to describe it as a material object
(VAN INWAGEN, 1990, p. 17).

In this initial form, the characterization of the physical presented by the (Object) criterion was never employed in a formulation of physicalism.

2 The distinction is suggested by Markosian (2000, pp. 382f.). 
This might be explained by the fact that the macroscopic objects that we intuitively call physical are not expected to instantiate mental states and other higher-level phenomena. However, the set of intuitively recognized physical objects seems to embrace more than just macroscopic objects. Markosian claims it is natural to think that (...) every part of a physical object must itself be physical' (MARKOSIAN, 2009, p. 487). If this is so, then the parts of intuitively recognized physical objects should also be conceived as physical objects. In this elucidated form, the characterization of the physical presented by the (Object) criterion played a major role in the history of the different formulations of physicalism. Some classical formulations were based on characterizations of the physical that referred to objects presumed to be the most fundamental parts of intuitively recognized physical objects.

The classical atomism is an example of a physicalist thesis informed by a characterization of the physical that extends over what was, at the time, presumed to be the most fundamental parts of macroscopic physical objects. It states that classical atoms, a priori conceived as indivisible microscopic objects that possess most of the basic properties that are found amongst macroscopic objects, constitute and necessitate everything there is (STOLJAR, 2010, p. 58). The seventeenth-century materialism is another example.

The classical atomism and the seventeenth-century materialism were abandoned because they were proven false by physics. Newton's discovery of gravitation played a major role in the abandonment of such forms of physicalism and, since then, physicists have uncontroversially acknowledged many other phenomena inconsistent with these formulations of physicalism.

The reason for abandoning these two theories reveals why any characterization of the physical solely based on the (Object) criterion cannot be employed as an answer to PPP. The lesson is to be drawn from the fact that the seventeenth-century materialism and the classical atomism 'attempted to limit physics a priori' (CRANE and MELLOR, 1990, p. 186). A characterization of the physical that restricts its domain to intuitively recognized physical objects and their parts, which are considered to be physical objects as well, runs into the same error. Indeed, some views concerning modern physics emphasize that some of the phenomena with which it is concerned 'are not intuitively physical objects, and do not have the properties distinctive of intuitively physical objects' (STOLJAR, 2010, pp. 62-66). The reason why these characterizations of the physical are unsuccessful can be formulated as a difficulty, which constrains the search for a solution to PPP:

Diff. 1: The physical cannot be characterized independently from what the theories of physics postulate. 


\section{The (Theory) criterion approach}

In contrast to the (Object) criterion for the use of the term 'physical', the (Theory) criterion has played a significant role in determining the contemporary debate on the notion of physical. The claim it conveys, i.e., that the physical are the things expressed by the predicates of physical theories, admits different characterizations of what is physical. These characterizations distinguish themselves by means of the physical theories that are taken into account, since they restrict the set of predicates that should be thought to refer to genuine physical entities.

There are different notions of physical that correspond to different periods in the history of physics. It is reasonable that contemporary partisans of physicalism should not trust the plausibility of this doctrine to characterizations of the physical extracted from physical theories of the past. All former stages of physics are expected to fail to offer an appropriate notion of what is physical, if current physics is considered as an improvement over them. The term 'current physics' is understood here as the set of physical theories considered by contemporary physicists as our best theories. The expression 'physics of the past' (in the plural) refers to sets of physical theories that were formerly advocated at the same time. Each of these sets must differ from the set of theories that composes our current physics. Similar to the case of current physics, the physical theories that compose a physics of the past are theories that were held by a group of physicists during a certain period in former times.

Conceived as possible sources for a characterization of the physical that might solve PPP, current physics has, indeed, a primacy over any physics of the past. This primacy follows from the two ways in which they can diverge. Firstly, a physics of the past may have posited putative physical things that later on were acknowledged as nonexistent. Secondly, it may have restricted the scope of physics in a way that some, nowadays acknowledged physical things were not included. It is important to emphasize that a physics of the past must diverge from current physics in at least one of the two ways just mentioned.

Because of the divergence with current physics, any determinate physics of the past must be avoided in a formulation of physicalism. All physics of the past are inadequate to offer a notion of the physical to physicalism because the derived formulations of physicalism will be considered false in at least one of the following ways. Either they:

(a.) posit putative physical things that, in accordance to current physics, do not exist, or

(b.) they fail to include among the physical, and therefore among what there is, things now recognized as physical. 
If (a.) is the case, i.e., if some formulation of physicalism posits the existence of something that we know that does not exist, then this formulation must be considered false. If only (b.) is the case, i.e., if some formulation of physicalism offers an incomplete account of what we now take to be physical, then it must be considered false since it also offers an incomplete account about what there is. It is a bit trickier to justify the claim, according to which any formulation of physicalism that falls on the case (b.) must be considered false. The problem is that even if a formulation of physicalism fails to include something currently acknowledged to be physical among the set of things it explicitly presents as physical, its account of what there is not necessarily incomplete. It is possible that the formerly ignored, but currently acknowledged physical entities are realized by the things referred by the predicates of a physics of the past. Thus, the non-explicitly mentioned (and nowadays acknowledged) physical things could still be included in the account of what there is. It seems, however, that this possibility is completely undermined by a feature of the latest developments of physics. Some branches of current physics have revealed constituents of the physical world that are more fundamental than the ones postulated by any physics of the past. If this interpretation of the latest development of physics is correct, then it precludes that any set of things presented as physical by some physics of the past could include or necessitate all the things expressed by the predicates of current physical theories. No set of less fundamental entities could necessitate more fundamental ones.

We have seen the reasons why a notion of the physical based on predicates of a physics of the past cannot figure in a plausible formulation of physicalism. For similar reasons, however, a notion of the physical extracted from the theories of current physics might also be inadequate. The theories of physics that are accepted now are neither true above any doubts, nor expected to offer a complete account of the physical reality. On the contrary, it is expected that, as time goes by, some of these theories might fall, others might be improved, and that new ones might be introduced.

The inadequacy of a notion of physical determined by the predicates used in current physics is emphasized in the first horn of Hempel's dilemma. The second horn stands against any attempt to base physicalism on some future or ideal physics. The dilemma was originally presented as a critique to the sort of linguistic or semantic physicalism proposed by Otto Neurath and Rudolf Carnap (HEMPEL, 1980, pp. 194f.). Physicalism is conceived nowadays primarily as a metaphysical doctrine, which would not be clearly endangered by the original formulation of the dilemma. Geoffrey Hellman has formulated the following version of Hempel's dilemma that explicitly stands against any tentative characterizations of physicalism as a metaphysical doctrine: 
(...) current physics is surely incomplete (even in its ontology) as well as inaccurate (in its laws). This poses a dilemma: either physicalists principles are based on current physics, in which case there is every reason to think they are false; or else they are not, in which case it is at best, difficult to interpret them, since they are based on a "physics" that does not exist-yet we lack any general criterion of "physical object, property, or law" framed independently of existing physical theory (HELLMAN, 1985, p. 609).

Let us consider the two horns of the dilemma in more detail. The first horn says that if physicalism were based on current physics (for now on referred to as 'current physics physicalism'), then it would be most probably false. This conclusion follows from the fact that current physics might be false or incomplete as any physics of the past. The current physics physicalism might, thus:

(a'.) posit something as existent, that in fact does not exist; or

(b'.) fail to include among the physical, and therefore among what there is, something that is physical.

Similar to what occurs with the formulations of past physics physicalism, if one of these possibilities occurs, then current physics physicalism is false. However, in contrast to past physics physicalism, there are no available physical theories that falsify current physics physicalism. There is only the supposition that it is false, which is based on two important reasons. Firstly, the history of physics has been characterized by a continuous abandonment of formerly uncontroversially acknowledged theories in favor of new ones, which exhibit greater explanatory power. Secondly, physicists and philosophers of physics agree 'current physics is full of unfinished business' (BUTTERFIELD and EARMAN, 2007, p. xx). Considered in conjunction, these two reasons make current physics physicalism very unattractive. Considerations about past and current physics physicalism reveal another difficulty that constrains the search for a solution to PPP:

Diff. 2: The characterization of the physical cannot be based on a physics that is a false or incomplete.

The second horn of Hempel's dilemma stands against formulations of physicalism that, by referring to future or ideal physics, try to avoid the dangers that justified our disbelief towards the current physics physicalism. David Armstrong has influentially pursued this approach. He asserts that ' $\mathrm{t}$ ] $\mathrm{he}$ Materialist is not committed to the current set of properties to which the physicist appeals, but he is committed to whatever set of properties the 
physicist in the end will appeal to' (ARMSTRONG, 1991, p. 186). Armstrong's suggestion is ambiguous, but only to a minor and harmless degree. The physical theories that are expected to be acknowledged by the physicists in the end can be thought to constitute an ideally complete physics that, in peircean terms, is reached at the limits of inquiry (cf. STOLJAR, 2010, p. 95). However, one can also maliciously interpret Armstrong words as if they referred to the last set of physical theories that will be actually acknowledged by humankind. I think this reading does not correspond to Armstrong's position. If such future physics is not the ideally complete physics, it fails to avoid the dangers that threaten current physics physicalism. Only the first reading of Armstrong's formula let us avoid the dangers presented in first horn of Hempel's dilemma ${ }^{3}$. However, as mentioned before, a formulation of physicalism based on an ideal physics (for now on referred to as ideal physics physicalism') is a target of the second horn of the dilemma.

According to Hempel's dilemma, both the theories of an ideally complete physics and the physicalism that is formulated in accordance to them are 'unclear' and 'difficult to interpret'. Hempel has previously criticized the way of approaching a science that informs the notion of an ideal physics. In his words, it is 'an extremely elusive idea' to refer 'not only to the theories actually formulated at one time or another in the past, present, or future, but simply to any conceivable true theory [of the respective science]..., whether or not it is actually ever thought of and formulated' (HEMPEL, 1969, p. 182).

In order to deal with these objections in a systematic way, I interpret the second horn of Hempel's dilemma as stating that we should avoid committing ourselves to the ideal physics physicalism because its content is indeterminate ${ }^{4}$. The argument leading to this conclusion has many stages. Firstly, we conclude that the content of an ideally complete physics is indeterminate. Since physics has not reached the limits of inquiry, we cannot know which theories might compose it at this stage. Secondly, we conclude that the notion of physical also lacks determination. If the theories are not available, we cannot know which kinds of entities are referred by their predicates, i.e., we cannot know what is physical in accordance with these theories. Finally, by not being able to offer a characterization of what is physical, the content of the ideal physics physicalism is left indeterminate. Just

\footnotetext{
${ }^{3}$ Barbara Montero offers a similar argument in favor of this reading. According to her, when a physicalist appeals to the idea of a final physics, he does not mean 'the temporal end of physics. For this physics might still be inaccurate or incomplete; even worse, for all we know, physics might regress.' (MONTERO, 1999, p. 192).

${ }^{4}$ Contrary to a common interpretation of the second horn of Hempel's dilemma (cf. WILSON, 2006, p. 67), I prefer to distinguish it from Chomsky's objection that a complete physics physicalism might be trivial by means of an inappropriate extension of the subject of physics. The main reason for distinguishing them follows from the fact that, according to Smart's testimony (SMART, 1978, p. 339), Chomsky's objection was made public previously.
} 
by considering an ideally complete physics, we are not able to make sense of the statements 'everything there is is physical' and 'there is nothing over and above the physical.' Physicalism remains unintelligible. Thus, the problem presented by the second horn of Hempel's dilemma constitutes another difficulty for any attempt to solve the physicalist problem of defining physical:

Diff. 3: The characterization of what is physical must have a determinate content.

Besides the criticism that the ideal physics physicalism might have an indeterminate content, this doctrine was criticized as being possibly trivial. Chomsky was the first to emphasize that, in the future, physics can include in its domain of investigation mental states and other features currently conceived as antithetical to physicalism. Just as Newton introduced gravitation to physics, in a time in which contact was conceived to be the only possible cause of movement, mental states and every other apparently non-physical phenomenon might be introduced in the scope of physics in a certain stage of its development (CHOMSKY, 1980, p. 6). If this is possible, then physicalism might be trivial. The objection that the ideal physics physicalism can be a trivial thesis can be made even stronger. Physics is conceived as a science aiming at a complete account of the world's fundamental features. Thus, if mental states are revealed to be fundamental, not realized by anything, then there is a reason to include them among the physical. If physics fails to explain mental states, just including the latter in the scope of physics might fulfill the task of offering a complete account.

Mental states can be unproblematically 'included' in the scope of physics if they are identical with entities that are otherwise acknowledged as being physical. If a mental state is identical with a physical entity, then it is part of the physical domain. The sort of abstruse inclusion that would make physicalism trivial is that of mental states or entities that are not physical things (cf. STOLJAR, 2010, p. 82). In order to avoid this sort of problematic inclusion, a characterization of physicalism must face the following difficulty:

Diff. 4: The characterization of the physical cannot allow that mental states that are not identical to physical things, as well as other things that differ from physical things, might be included in the physical domain.

\section{Rejecting current physics physicalism}

Let us draw our attention again to the four difficulties that, according to what has been argued, constrain the search for a solution to PPP: 
Diff. 1: The physical cannot be characterized independently from what the theories of physics postulate.

Diff. 2: The characterization of the physical cannot be based on a physics that is a false or incomplete.

Diff. 3: The characterization of what is physical must have a determinate content.

Diff. 4: It cannot allow that mental states that are not identical to physical things, as well as other things that differ from physical things, might be included in the physical domain.

The characterization of the physical based on the theories of the ideal complete physics is the most successful amongst the former attempts to solve PPP considered here. It easily overcomes the first two difficulties. The notion of physical presented by the ideal complete physics is not independent on what the physical theories postulate. In contrast to the notion of the physical derived from by the (Object) criterion, the (Theory) criterion approach assigns to physics a significant role in determining what is physical. Even if we do not know which are the physical theories that compose the ideal physics, it determines this notion by means of such theories. Moreover, an ideal complete physics cannot be false or incomplete. By definition, it consists in a set of true theories whose scope covers all the features of reality that might concern physics.

Some physicalists have espoused current physics physicalism. Jack Smart, Geoffrey Hellman and Andrew Melnyk argue that the incompleteness and the fallibility of current physics is not enough to impair current physics physicalism in significant respects. For Smart (1978) and Hellman (1985), physicalism can achieve the goal of presenting a theory about the mental phenomena by means of current physics. According to them, the forthcoming progress in physics will not change the current 'physics of ordinary nature' (SMART, 1978, p. 340) or the 'classical (i.e., nonquantum) mechanics' (HELLMAN, 1985, p. 610), which they claim to be sufficient for explaining the referred phenomena. However, the view that a theory about the mental phenomena can be formulated by means of physical theories that have a lower probability of being modified (the classical, nonquantum, physics in Hellman's terms) is controversial. David Chalmers, for instance, claims that 'one cannot rule out the possibility that fundamental physical theories such as quantum mechanics will play a key role in a theory of consciousness' (CHALMERS, 1996 , p. 120). Besides that, many arguments against physicalism in general suggest the irreducibility of consciousness and of the intentionality of mental states. Therefore, the view that current physics physicalism can offer a theory of the mental phenomena cannot be taken for granted.

Melnyk's defense of current physics physicalism is of another sort. In his view, despite the fact that it is very likely false, physicalists should not 
abandon current physics physicalism, because it is 'a hypothesis with a higher probability than that of its relevant rivals' (MELNYK, 1997, p. 625). Melnyk defines 'relevant rivals' in the following way:

Hypothesis $\mathrm{H} 1$ is a relevant rival to $\mathrm{H} 2$ if and only if (a) $\mathrm{H} 1$ is sensibly intended to achieve a significant number of H2's theoretical goals; (b) the hypothesis, $\mathrm{H} 1$ and $\mathrm{H} 2$, fail to supervene on one another; and (c) $\mathrm{H} 1$ has actually been formulated (MELNYK, 1997, p. 626).

He makes an impressive case in demonstrating that current physics physicalism might have a higher probability than the rival hypotheses that satisfy the conditions just specified. However, it is not clear how the condition (c) works. More specifically, it is not clear whether a rival hypothesis that "has actually been formulated' must have a completely determined content. In a footnote in the book $A$ Physicalist Manifesto, Melnyk seems ready to acknowledge the higher probability of a rival hypothesis that does not completely specify the contents of the notions it employs. This rival hypothesis says that the basis over which everything else is necessitated does not only include the things referred by current physics, but also 'at least one further entity that has features and magnitudes similar to those spoken of as such in current physics' (MELNYK, 2003, pp. 236f.). If this hypothesis satisfies all conditions for being a relevant rival to current physics physicalism, then there is no alternative for physicalists other than to abandon the latter. Such abandonment is justified not only by the fact that it is most likely false, but also because there is at least one more probable hypothesis available.

Besides the problems already mentioned, the arguments presented by Smart, Hellman and Melnyk in favor of current physics physicalism fail in an important respect. They do not exempt current physics physicalism from the objection that it most likely offers a false answer to the metaphysical questions of what there is and how the world is like. As a metaphysical doctrine, current physics physicalism is most likely false, and, therefore, should be abandoned.

A characterization of physical that corresponds to the theories of the ideal physics is the only one able to overcome Diff. 2. However, there are reasons to avoid this characterization, which are derived from the last two difficulties described above. According to a very intuitive view, the content of physics at the limits of inquiry is left indeterminate ${ }^{5}$. Since the characterization of the physical would be discerned by means of the predicates of such physics, what is physical would also remain indeterminate. Apparently, by not being able to overcome Diff. 3, the referred attempt to solve PPP does not seem to exclude mental states and other antithetical entities from the scope of

${ }^{5}$ van Fraassen (1996, p. 173): 'Aiming the completeness claim at science in the long run empties it of content, since no one today can know what science will eventually be like.' 
physics. Since what is physical is said to correspond to the scope of physics, this attempt to characterize the physical would also fail to overcome Diff. 4. Thus, one might conclude that a characterization of what is physical that is based on the complete ideal physics should be abandoned as another failed attempt to solve PPP. In what follows, I argue against this conclusion.

\section{On the content of the ideal physics}

It would be possible to determine the content of the ideal physics to a certain extent if we could show that it shares some content with the current physics. According to Barbara Montero, some authors have tried 'to carve a path between the two horns of Hempel's dilemma (...) by taking the true and complete physics at issue to be a successor to today's physics' (MONTERO, 2009 , p. 184). Different aspects of current physics can be said to take part in the ideal physics. One could claim that some current physical theories are true. However, in spite of their success in explaining and predicting phenomena, the physicalist should not rely on that. The examples of discarded past physical theories justify the disbelief on the truthfulness of our most reliable current physical theories. In the words of John Worrall, 'no present day realist would claim that we have grounds for holding that presently accepted theories are true (1989, p. 104). Notwithstanding the fact that they might not share theories, it is possible that past and current physics share with the ideal physics their domain of investigation to a certain extent.

Until now, this paper has only discussed attempts to characterize the physical that are based on the (Object) or the (Theory) criterion. In the following, I defend that if we take both elements of the philosophical concept of physical into account, we are able to demonstrate that the current and the ideal physics share some content. My thesis is that they share their domain of investigation to a significant extent.

As described above, the (Object) criterion presents as physical the things that we intuitively recognize as physical objects. This recognition, I have argued, is mediated by an everyday concept of physical objects. Following Markosian, I have also claimed that it is natural to conceive the parts of macroscopic physical objects as being also physical objects. Thus, the (Object) criterion would not only present macroscopic objects as being physical, but also their microscopic parts.

The attempt to solve the physicalist problem of defining physical by means of the (Object) criterion fails because it imposes a priori a restriction upon physics. To avoid this consequence, the majority of the contemporary physicalists pursue solutions to PPP that are solely guided by the (Theory) criterion. It is possible, however, to consider the (Object) criterion together with the (Theory) criterion. We have seen that the domain of investigation of 
physics cannot be restricted to the set of intuitively recognized physical objects. However, this does not mean that the latter cannot help us determine the former to a certain extent. Consider the hypothesis that intuitively recognized physical objects are among the things investigated by theories of the ideal physics. Indeed, current and past physical theories refer to such objects. We find generic references to physical bodies in physical theories, and some intuitively recognized physical objects are even presented in their specificity. Astronomy and particle physics offer good examples of the latter kind. The moon and other celestial objects instantiate all the features presented in van Inwagen's analysis of an everyday concept of physical objects. They occupy space and endure through time; they can move in space; they have a surface and a mass, and 'are made of certain stuff or stuffs' (cf. VAN INWAGEN, 1990, p. 17). The claim that the objects of particle physics fall under this notion is a bit more controversial. It is clear that sub-atomic particles do not instantiate all the features mentioned in van Inwagen's analysis. However, they rightfully fall under this notion if we acknowledge another intuitive criterion for recognizing physical objects, namely, that of being a part of a physical object.

The controversy about the inclusion of sub-atomic particles among the intuitively recognized physical objects reveals the lack of precision of our everyday notion. In order to solve this problem, we could stipulate a definition of 'physical object' that would avoid such indeterminacy. With this aim in mind, Markosian offers an alternative characterization of physical objects. His 'Spatial Location Account of Physical Objects' claims that 'a physical object is an object with spatial location' (MARKOSIAN, 2000, p. 377). In contrast to the 'Common Sense Account', the account he proposes has the advantage of uncontroversially acknowledging quarks, electrons, etc. as physical objects (MARKOSIAN, 2000, pp. 383f.). Despite the fact that a stipulative definition would be advantageous in this respect, there is a strong reason to preserve the everyday concept in its original, indeterminate form. Markosian's precise characterization of physical objects abstracts away one or more features that we usually assigned to them. However, by drawing our attention to current and past physics, we notice that some physical theories have been formulated in order to explain these features.

There are features instantiated by intuitively recognized physical objects with which physics has never been concerned. The function of a hammer and the beauty of a certain oil painting, for example, have always been outside its scope. Only the features we assign to those objects in virtue of recognizing them as physical, i.e., the features that make them physical bodies, are appropriate subjects of physical investigations. The motion, the mass, as well as the spatial and temporal locations of physical bodies are, traditionally, subjects of physical theories. In respect to macroscopic objects, the features just mentioned are among the observable phenomena, which past 
and current physics were aimed to elucidate. The search for the most fundamental constituents of intuitively recognized physical objects is also traditionally acknowledged as a task for physics. Thus, the everyday concept of a physical object exhibits a greater influential role in determining the scope of physics than Markosian's clear-cut stipulative characterization of a physical object.

The fact that intuitively recognized physical objects (and their general features) take part in the domain of investigation of current physics does not imply that they restrict it. In the cases of particle physics and astronomy, for example, energy is acknowledged to be a topic of investigation as relevant as particles and celestial bodies. Under scrutiny, the things referred in the theories of current physics reveal themselves to be of radically different kinds. Notwithstanding the differences in their nature, a significant portion of the things investigated by current physics do not differ in one respect: they take part of an explanatory nexus prompted by investigations of the general features of intuitively recognized physical objects.

I have claimed that there are physical theories that refer to intuitively recognized physical objects and their general features. Analogous to the case of biology, which investigates living organisms and the non-living things that are strongly related to living organisms, I maintain that the things that are strongly related to those physical objects are also relevant to physics ${ }^{6}$. In order to explain and elucidate the behavior and the general features of intuitively recognized physical objects, physics has presented theories, which refer to putative entities that are neither macroscopic physical bodies nor their microscopic parts. Nonetheless, there is a reason to consider those things as physical. In accordance to the (Theory) criterion, they are theoretically acknowledged physical entities.

It is possible that the features attributed to the mentioned theoretically acknowledged physical entities also demand elucidation. If this is so, and since physics is conceived to be the most fundamental science, its domain of investigation is much larger and diverse. It includes entities that are referred to in theories that explain the features and the behavior of formerly theoretically acknowledged physical entities. The limit of this explanatory nexus lies on the most fundamental level.

After characterizing physical objects as the entities that possess spatial location, Markosian describes physics as 'the science of physical objects and the laws of nature that govern them' (MARKOSIAN, 2000, p. 384). Maybe the scope of physics is ultimately restricted to entities with spatial locations. However, the possibility that physics might contradict this a priori restriction of its domain of investigation makes his view problematic. My

${ }^{6}$ The expression 'strongly related' is vague. I employ it to suggest that intuitions play some role in determining the limits of the subject of investigation of a natural science. 
suggestion is to consider the a posteriori evidence that physics has, among others, the task of explaining and elucidating the behavior and the general features of intuitively recognized physical objects. Hence, I take different kinds of things to be on its scope. The macroscopic physical bodies and their microscopic parts, and the features we generally assign to those things compose just a restricted subset. In addition, the theoretically acknowledged physical entities to which we refer in order to explain and elucidate those things are physical; as well as other entities to which we refer in order to elucidate the features of formerly theoretically acknowledged physical entities, and so on.

The ideal physics, i.e., the physics at the end of inquiry, is an idealization of the current physics in respect to the success in the pursuit of its aims. Since current physics has the explanatory task I attributed to it, as shown by a posteriori evidence, then the ideal physics can be conceived as comprehending true theories that thoroughly elucidate the features of intuitively recognized physical objects. It is possible that the theories formulated in order to accomplish this explanatory task refer to entities whose features demand elucidation by means of other theories. Thus, an explanatory nexus is formed, which is composed by true theories that thoroughly elucidate the features of the intuitively recognized physical objects and, if there are any, the features of other theoretically acknowledge physical entities. Stoljar suggests in a summary manner a similar account of physical theories as the theories needed to fully explain the nature and the behavior of physical objects (cf. 2010, pp. 73f.). As indicated in the section 6 of the present paper, Stoljar opposes any solution to PPP based on the (Theory) criterion approach.

Since we should not hold the theories of current physics as being true, we are not able to determine the theories of the ideal physics that take part in the mentioned explanatory nexus. However, by considering the explanatory nexus as a successful accomplishment of one of current physics' explanatory tasks, we can determine to a certain extent the ideal physics' domain of investigation. Firstly, it includes the macroscopic physical bodies and their general features, as well as the microscopic parts of those objects and their general features. Secondly, it includes the entities (i.e., theoretically acknowledged physical entities) that might play some role in determining the behavior and the general features of the intuitively recognized physical objects. Thirdly, it includes the entities that might play some role in determining the features of other formerly theoretically acknowledged physical entities; and so on, towards the most fundamental level.

Let us return to Diff. 4. It demands a constraint in determining the content of the ideal physics. If we wish to avoid trivializing physicalism, mental entities that are non-physical cannot be included in the domain of physics. Prima facie we can overcome this difficulty by acknowledging another element of the cluster concept that constitutes our philosophical concept of 
physical, namely, the (Contrast) criterion. The presence of the (Contrast) criterion in the cluster concept consists, indeed, in an a priori reason for excluding the problematic mental entities from the domain of the physical. It says that the term 'physical' does not apply to any mental entity (substance, property, etc.) that cannot be, by definition, identical with something physical. However, the a priori restriction that follows from the (Contrast) criterion is not enough. As was the case with former attempts made by philosophers to restrict the domain of the physical a priori, physics might just ignore it, and eventually force philosophers to modify their concept of physical. Montero recognizes the lack of influence a philosophical concept of physical may have, but also indicates a way in which philosophers might claim that the problematic mental states are excluded from the physical domain. She says:

(...) physics will proceed as it will proceed regardless of what restrictions philosophers place on its development. However, philosophers can make empirical claims; and perhaps the claim that this true and complete physics will not involve mental properties is a perfectly acceptable empirical claim (MONTERO, 1999, p. 192).

Jessica Wilson (2006) also acknowledges the inefficacy of an attempt to argue a priori for the exclusion of the problematic mental entities from the physical domain. However, she goes further than Montero, in the sense that she offers a posteriori reasons in favor of this exclusion. In contrast to Montero, who suggests us to make an empirical claim, Wilson presents a constraint, which she calls 'the NFM (no fundamental mentality) constraint' (2006, p. 70). The NFM constraint says that a physical entity is not fundamentally mental (that is, does not individually either posses or bestow mentality)' (2006, p. 72).

Wilson offers two reasons in favor of NFM, which consist in 'relevant historical and pragmatic considerations' (2006, p. 84). The historical consideration emphasizes the significant role played by the NFM constraint in preserving the sense of materialism as an anti-dualist doctrine (2006, p. 85). Wilson argues that the exclusion of any fundamental mental entity from the physical domain also plays a significant pragmatic role in 'providing a basis for [formulating] the mind-body problem' (2006, p. 90). According to her, these reasons reveal that the incompatibility between the fundamental mental entities and physics can be argued a posteriori. Additionally, she claims 'considerations about what is a priori about the physical are effectively useless in determining whether physical entities should be subject to the NFM constraint' (2006, p. 84).

Despite agreeing with Montero and Wilson in respect to the inefficacy of an a priori argument for excluding the problematic mental states from the physical domain, I claim, contra Wilson, that the recognition of the (Contrast) criterion in our notion of physical plays a useful role in 
characterizing the physical. Although the mentioned historic and the pragmatic considerations serve as better reasons for restricting the domain of the physical, the (Contrast) criterion indicates this restriction. Besides, it has originally determined the philosophical debates that make the historical and pragmatic considerations true.

\section{Some objections and responses}

An objection to the account proposed here consists in the claim that the ideal physics may accomplish the mentioned explanatory task by means of more than one set or body of theories. I do not think it is possible to decide from the armchair whether this scenario consists in a real possibility or not. However, we are able to conclude that it contradicts the form of scientific realism that is endorsed by the usual formulations of physicalism. If there is more than one complete and true explanatory nexus that explain the features of intuitively recognized physical objects, etc., then the world is not such that science can accurately describe it. By denying scientific realism, the objection turns out to be a general objection to physicalism. However, it also becomes weaker. Physicalists can conceive the mentioned objection as a kind of pessimism, and respond to it as scientific realists did, namely, with reasons for optimism (see GODFREY-SMITH, 2003, pp. 176-179).

Another objection appeals to the possibility that there might not be a fundamental level in the physical domain. The notion of a complete ideal physics is committed to the thesis that there is a fundamental level demarcating the limits of physical investigations. The fundamental level has been characterized in different ways. According to Jonathan Schaffer, proponents of a fundamental level usually characterize it as 'a level of entities that have no proper parts' (SCHAFFER, 2003, p. 500). This characterization is not compatible with the possibility that, instead of a level of mereological atoms, there is an infinite descent or divisibility. According to Schaffer, there is no a priori reason (SCHAFFER, 2003, pp. 501f.), nor enough a posteriori evidence (SCHAFFER, 2003, pp. 504f.) to justify the abandonment of the thesis of an infinite descent. It is risky, thus, to base the notion of an ideal complete physics on the characterization of the fundamental level that posits entities with no proper parts.

Schaffer suggests an alternative characterization of the fundamental level that does not exclude the possibility of an infinite descent. The metaphysical thesis he entitles 'supervenience-only fundamentality' posits 'a point in the mereological hierarchy bellow which all remaining mereological divisions are boring' (SCHAFFER, 2003, p. 509). Divisions are said to be boring, in his sense, if 'the characteristic properties of all the parts supervene on the characteristic properties of their wholes' (SCHAFFER, 2003, p. 505). It 
is not clear to me how we should understand the whole-part supervenience relation. The illustrative cases given by Schaffer, 'Pascal's worlds-within-worlds picture' (2003, p. 505) and the story about 'turtles all the way down' (2003, p. 509), are not very helpful. It is helpful, however, to notice the role that is attributed to properties in demarcating the fundamental level. As in the usual characterization, the components of the fundamental level can be, according to Schaffer's supervenience-only fundamentality, entities without parts. The novelty brought by his account consists in the claim that also entities that have parts may be fundamental. They are fundamental if the relation between their properties and the properties of the whole satisfy a certain condition: the properties of these entities must be determined by the properties of the whole of which they are parts. To use Schaffer's terminology, let us call these determinations 'boring.'

Barbara Montero has offered a characterization of the fundamental level in which properties play a significant role. According to her, the fundamental level consists in a level of fundamental properties, i.e., properties that are 'not determined by other properties' (MONTERO, 2006, p. 179). Prima facie, this characterization is not compatible with the idea of an infinite descent or divisibility. However, it seems that a property could still be considered fundamental if its instantiations were only determined by instantiations of the same property. Consider the property that cubes share, namely, of being a symmetrical three-dimensional shape contained by six equal squares. The instantiations of this property in eight equally sized cubes can determine the instantiation of the same property in a larger cube. Despite the fact that it would be a relation of determination, the property of the larger cube does not seem to belong to a higher level. I do not know whether this determination can be conceived as boring in the sense elucidated above, i.e., as being a case in which properties of the parts are also determined by properties of the whole. It is clear, however, that it is a case in which instantiations of a property in the parts determine an instantiation of the same property in the whole. In order to contrast with the whole-part supervenience relation, I call the determination of a property instantiation by means of instantiations of the same property 'monotonous.'

Instead of evaluating the merits and problems of each of the characterizations of the fundamental level, I will suggest another characterization of the fundamental level, which boroughs features from the ones just mentioned. I acknowledge two reasons for offering yet another characterization of the fundamental level. Firstly, the characterization must adequately demarcate the limits of physics. If the fundamental level is characterized as consisting only of atoms and/or properties, this would imply that, in this level, physics would be restricted to these ontological categories. In order to avoid this unnecessary restriction, I refer to the components of the fundamental level with the more general terms 'things' and 'entities.' Secondly, 
it seems that boring and monotonous determinations, as described above, have an aspect in common. They have in common the fact that they present a part-whole relation in which properties of the parts cannot be considered to be of a lower level in respect to the properties of the whole. In the case of boring determinations, the properties that determine something (the properties of the parts) are also determined by (or supervene on) the properties of the thing they determine (the whole). In the case of monotonous determinations, the properties that determine something (the properties of the parts) are instances of the same property whose instantiation they determine (in respect to the whole). By referring to the fact that the properties that determine cannot be conceived as belonging to a lower level in respect to the properties that are determined, I am emphasizing what both sorts of determination, monotonous and boring, have in common.

In accordance with the reasons I have given, I characterize the fundamental level as being composed by: the things that are not determined by anything else; and the things that are determined only by other entities, whose properties cannot be conceived to belong to a lower level in respect to the properties of the former. If something can be otherwise determined, it does not belong to the fundamental level.

The characterization of the fundamental level just given appropriately describes a possible limit for physical investigations. The explanatory nexus presented by the complete ideal physics would be delimited by things that are not determined by anything else and the things that are exclusively determined by other things whose properties cannot belong to a lower level. It is possible, however, that there are no such things. If there is an infinite descent marked by determination relations of properties that rightfully belong to lower levels (in other words, if the determinations are interesting all the way down), then there is no fundamental level, and physics cannot be complete.

Finally, I would like to deal with an objection raised by Stoljar (2010) to characterizations of what is physical in physicalism by means of the (Theory) criterion. According to Stoljar, such characterizations would either be based on the physical theories of the actual world or on the physical theories of possible worlds. He argues that both alternatives are problematic, and concludes that the (Theory) criterion approach to solve PPP fails.

The reason offered by Stoljar to dismiss the (Theory) criterion approach to PPP is that both accounts seem to be incompatible with strong intuitions about physicalism. More specifically, he claims that if the notion of physical for physicalism is determined by the physical theories of the actual world, physicalism would be false in possible worlds in which our intuitions suggest it is true. However, if the characterization of what is physical is determined by the physics of possible worlds, Stoljar claims that physicalism would be true in worlds in which, according to our intuitions, it is expected to be false. He presents hypothetical scenarios to argue in favor of the mentioned 
conditionals.

In his justification of the first conditional, Soltjar asks us to consider a world in which twin-mass, twin-charge, and twin-spin necessitate the instantiations of all properties of the world (STOLJAR, 2010, p. 77). Twinmass, twin-charge, and twin-spin are similar to mass, charge and spin in the actual world, but are not mentioned in the theories of the actual world physics. According to our intuitions, physicalism is true in the twin world just described, since it has no fundamental mental entity. However, if the notion of physical for physicalism is determined by the physics of the actual world, physicalism is false in the twin world, since it contains entities that are not physical in its fundamental level.

Stoljar presents different possible worlds in his defense of the second conditional. He calls them 'the classical dualist world', 'the primitive color world', 'the vitalist world' and 'the emergent chemistry world' (STOLJAR, 2010, pp. 80-85). These possible world have some aspects in common. Stoljar conceives their fundamental level, from which everything else is necessitated, as being inhabited by entities that would, according to our intuitions, make physicalism false. The respective entities are souls, irreducible colors, élan vital and emergent chemical properties. These hypothetical scenarios are also designed in a way that one cannot explain the nature or the behavior of physical objects in them without mentioning the entities that are problematic for physicalism. Stoljar argues that this last aspect determines a significant feature of the physics of these possible worlds. Given that physics consists in the theories that explain the nature or the behavior of physical objects, the physics of the classical dualist world would have predicates referring to souls, while in the vitalist world, physics would refer to élan vital, and so on. In characterizing what is physical by means of possible worlds physics we would make souls, irreducible colors, élan vital and emergent chemical properties physical entities of the worlds we take into account. Consequentially, and contrary to our intuitions, physicalism would be true in these hypothetical scenarios, since there would be nothing that is not physical amongst the things that necessitate everything else.

In responding Stoljar's objection to solutions to PPP based on the (Theory) criterion, I will only address the problem he presents to the strategy of extracting the notion of physical from the physics of possible worlds. In my opinion, the problem involved in a characterization that extracts the notion of physical from actual world physics is sound ${ }^{7}$. As indicated above, Stoljar argues that by appealing to possible worlds physics in an attempt to solve PPP, one makes physicalism true in worlds in which, according to our intuitions, it should be false. I suggest bellow a way out of this problem.

${ }^{7}$ See Baltimore (2013) for a criticism of this point. 
Contra Stoljar, I claim that the physics of possible worlds do not include entities that are antithetical to physicalism, which is enough to guarantee the falsity of physicalism in the worlds inhabited by such entities exist. As a reason in favor of this claim, I present the fact that the ideal physics of a possible world that matters to this sort of investigation is always conceived from our perspective. Thus, it is conceived in accordance with the relevant features of our notion of physical. Of course there are physicists in many possible worlds, doing physics from their own perspective. However, the physics of possible worlds' physicists do not matter to us when we ask if physicalism is true in their world, just as the stages of future physics do not matter to assess the truth of physicalism in the actual world. Since it is conceived from our perspective, the ideal physics of possible worlds are determined by the same general constraints that apply to the ideal physics of the actual world. Thus, the ideal physics of possible world are constrained by the same historical and pragmatic considerations that exclude from the ideal physics of the actual world entities that would falsify physicalism.

Interestingly, Stoljar acknowledges to a certain extent the efficacy of this way of dealing with the problem he formulated. By appealing to the (Contrast) criterion, he argues that we have a reason not to include souls in the physics of the classical dualist world, even though we are not able to explain the nature and the behavior of physical objects in this world without mentioning such entities (2010, pp. 81f.). Our (cluster) concept of physical demands us to leave out souls, ectoplasm and other putative fundamental mental entities from the physical domain. Nonetheless, Stoljar claims that the appeal to the (Contrast) criterion does not exclude from the domain of physics the entities that are antithetical to physicalism in the primitive color world, the vitalist world and the emergent chemistry world (2010, pp. 82-85).

As in the solution to Diff. 4, I will not rely on the (Contrast) criterion, but on a posteriori reasons for excluding entities from the domain of investigation of the ideal physics of possible worlds. In respect to the actual world, we do not feel the need to argue that the inclusion of irreducible colors, élan vital and emergent chemical properties in the physical domain would be abstruse. Our best scientific theories suggest that such things simply do not exist, so there is no need to worry with them. Notwithstanding our convictions, if we assume the possibility that we live in a world where élan vital, for example, plays a significant role in explaining the nature and the behavior of physical objects, we should start worrying with an abstruse inclusion in the physical domain. Reasons that are similar to the historical and pragmatic considerations presented in the solution of Diff. 4 apply here (cf. WILSON, 2006). The inclusion of irreducible colors, élan vital or emergent chemical properties in the physical domain would not allow us to preserve the sense of contrast between physicalism and the theories that postulate those entities. Besides, we would cease to acknowledge what makes those putative entities so 
strange to our eyes. This clearly applies to the cases of irreducible colors and élan vital. In the case of emergent chemical properties, there might not be historical and pragmatic reasons to leave them out of the domain of physics. But if this is so, then the truth of physicalism in the emergent chemistry world would not pose a threat for physicalism.

\section{Conclusion}

The paper dealt with the problem of characterizing what is physical in physicalism. Its main aim was to offer a solution to the mentioned problem, which would guarantee the intelligibility of physicalism. Former, unsuccessful attempts were considered in the course of the investigation. It was shown that these attempts were associated with either one or another element of a shared philosophical concept of physical. Among the reasons that made former attempts fail, one finds the horns of Hempel's dilemma and Chomsky's objection that physicalism can be made trivial by an inappropriate extension of the subject of physics. These reasons constitute difficulties that stand against any further attempt to characterize what is physical. A solution that overcomes such difficulties was presented here. In contrast to former attempts, the notion of physical that I proposed is more comprehensively informed by the different elements of our shared philosophical concept of physical. More specifically, I proposed a characterization of what is physical by an appeal to the ideal complete physics, whose content, I argue, is partially determined by features of intuitively recognized physical objects.

\section{Acknowledgments}

I would like to express my gratitude to Prof. Pirmin StekelerWeithofer (Universität Leipzig), Prof. Neil Roughley (Universität Duisburg-Essen), as well as to the participants of their research seminars. I am also grateful to Prof. Wilson Mendonça (PPGF - UFRJ), Prof. Guido Imaguire (PPGLMUFRJ) and the audience of the talk Fisicalismo e o Problema das Entidades Sociais Parte 1, presented at the Universidade Federal do Rio de Janeiro. I would also like to thank DAAD for the financial support.

\section{References}

ARMSTRONG, D. M. "The Causal Theory of Mind" In: The Nature of Mind, ROSENTAHL, David M. (Ed.), pp. 181-188, New York and Oxford, Oxford University Press: 1991. 
BALTIMORE, J. "Stoljar's Twin-Physics World” In: Philosophia, Vol. 41, pp. 127-136: 2013.

BRADDON-MITCHELL, D. and JACKSON, F.Philosophy of Mind and Cognition. Oxford: Blackwell Publisher, 1996.

BUTERFIELD, J. and EARMAN, J. "Introduction" In: Philosophy of Physics, Part A, . (Ed.), Amsterdam and Oxford, Elsevier: 2007.

CHALMERS, D.C. The Conscious Mind: In Search of a Fundamental Theory. New York and Oxford: Oxford University Press, 1996.

CHOMSKY, N. Rules and Representations. New York: Columbia University Press, 1980.

CRANE, T. and MELLOR, D. H. "There is No Question of Physicalism" In: Mind, Vol. 99, No. 394 (Apr. 1990), pp. 185-206: 1990.

GODFREY-SMITH, P. Theory and Reality: An Introduction to the Philosophy of Science. Chicago and London: The University of Chicago Press, 2003.

HELLMAN, G. "Determination and Logical Truth" In: The Journal of Philosophy, Vol. 82, No. 11, Eighty-Second Annual Meeting American Philosophical Association, Eastern Division (Nov. 1985), pp. 607-616: 1985.

HEMPEL, C. G. "Reduction: Ontological and Linguistic Facets" In:Philosophy, Science, and Method, MORGENBESSER, S., SUPPES, P., WHITHE, M. (Ed.), pp. 179-199, New York, St. Martin’s Press: 1969.

. "Comments on Goodman's Ways of Worldmaking” In: Synthese, Vol. 45 (1980), pp. 193-199: 1980.

MARKOSIAN, N. "What are Physical Objects?" In: Philosophy and Phenomenological Research, Vol. 61, No. 2 (Sep. 2000), pp. 375-395: 2000.

. "Physical Object" In: A Companion to Metaphysics, KIM, J., SOSA, E. and ROSENKRANTZ, G. S. (Eds.), pp. 486-489, Wiley-Blackwell: 2009.

MELNYK, A. "How to keep the 'Physical' in Physicalism" In: The Journal of Philosophy, Vol. 94, No. 12 (Dec. 1997), pp. 622-637: 1997. . A Physicalist Manifesto: Thoroughly Modern Materialism (Cambridge Studies in Philosophy). Cambridge: Cambridge University Press, 2003. 
MONTERO, B. “The Body Problem” In: NOÛS, Vol. 33, No. 2 (June 1999), pp. 183- 200: 1999.

. "Physicalism in an Infinitely Decomposable World" In: Erkenntnis, Vol. 64 (2006), pp. 177-191: 2006.

. "What is Physical?" In: The Oxford Handbook of Philosophy of Mind,McLaughlin, B., Beckermann, A., Walter, S. (Eds.), pp. 173-188, Oxford, Oxford University Press: 2009.

. and PAPINEAU, D. "A defense of the via negativa argument for physicalism” In: Analysis, Vol. 65, No. 3 (July 2005), pp. 233-237: 2005.

PAPINEAU, D. "Must a Physicalist be a Microphysicalist?" In: Being Reduced: New Essays on Reduction, Explanation, and Causation, HOHWY, J., KALLESTRUP, J. (Eds.), pp. 126-148, Oxford, Oxford University Press: 2008.

RYLE, G. The Concept of Mind. Harmondsworth: Penguin Books, 1968 [1949].

SCHAFFER, J. “Is There a Fundamental Level?” In: NOÛS, Vol. 37, No. 3, pp. 498-517: 2003.

SMART, J. J. C. "The Content of Physicalism" In: The Philosophical Quarterly, Vol. 28,No. 113 (Oct. 1978), pp. 339-341: 1978.

SPURRETT, D. and PAPINEAU, D. "A note on the completeness of 'physics”' In: Analysis, Vol. 59, No. 1 (Jan. 1999), pp. 25-29: 1999.

STOLJAR, D. Physicalism. London and New York: Routledge, 2010.

van FRAASSEN, B. "Science, Materialism, and False Consciousness" In: Warrant in Contemporary Epistemology: Essays in Honor of Plantinga's Theory of Knowledge, KVANVIG, J. L. (Ed.), pp. 149-181, Lanham, Rowan \& Littlefield Publishers, Inc.: 1996.

van INWAGEN, P. Material Beings. Ithaca and London: Cornell University Press, 1990.

WILSON, J. "On Characterizing the Physical” In: Philosophical Studies, Vol. 131 (2006), pp. 61-99: 2006. 
Dissertatio, UFPel [44 | 2016]

WORRAL, J. "Structural Realism: The Best of Both Worlds?” In: Dialectica, Vol. 43, No. 1-2, pp. 99-124: 1989.

Email: rasgouvea@gmail.com

Recebido: 09/2016

Aprovado: 12/2016 